\title{
GOLD NETTING TO STRENGTHEN FINANCIAL SYSTEM STABILITY
}

\author{
Ahamed Kameel Mydin Meera ${ }^{1}$
}

\begin{abstract}
Economic and financial crises seem to occur with increased frequency. Indeed now most countries, including several advanced economies like the US, Europe and Japan, are in serious economic recession. Employment and business opportunities have been much dampened. Inflation seems to be soaring globally and nations are witnessing widening gaps in income and wealth distribution. Many of these advanced economies are also facing shrinking population sizes that translate into aging problems and labor shortages. On top of those, there are environmental issues, including global warming. All these, in turn, have caused regional and global political conflicts and turmoil. The Arab Spring and the sovereign debt problems faced by some European countries like Greece are examples of this. Sustainability of economics and environment is thus of paramount concern of today. This paper considers those problems and suggests Interest-free Gold-based Electronic Netting System (IGENS) as an effective way of injecting liquidity into the economy, practically free, that can spur business and employment while bringing about structural stability, inflation checked with both economic and environmental sustainability. Netting or muqassah is a transaction allowed in shari'ah and is practiced worldwide in different forms. Examples include the highly successful WIR Bank of Switzerland, various Local Exchange Trading Schemes (LETS) and Bilateral and Multilateral Payment Arrangements between central banks.
\end{abstract}

Keywords: Global crisis, Payment system, Gold, Netting, Muqassah, Liquidity, Sustainability, Financial system stability

JEL Classification: E40, E42, E51

Received: October 23, 2016 ; Revised: July 26, 2017; Accepted: August 29, 2017

1 CEO of Z Consulting Group, Malaysia. Formerly he served as professor of finance and dean of the Institute of Islamic Banking and Finance, International Islamic University Malaysia. 


\section{INTRODUCTION}

The present global monetary system is plagued with myriad problems. It has become so vulnerable to crises one after another, from country to country, with increased frequency. Indeed now most countries are in economic recession. Even the major economies are not sparred; in fact it is the major economies that seem to be very much affected - the US, Europe and Japan are simultaneously in a liquidity trap where real interest rates are in the negative region. In most countries economic opportunities and business have been much dampened. Unemployment is on the rise while inflation seems to be soaring. All these also seem to cause some global and regional political conflicts and turmoil. The Arab Spring and the sovereign debt problems faced by European countries like Greece are examples of these. The global economic outlook for 2017 is bleak with the oil price is expected to remain low. Recently, the Royal Bank of Scotland warned its clients to "sell off everything" (except high quality bonds) in anticipation of a global meltdown that's even worse than that of 2008. Now what is actually going on? What brought the global economy to this precarious position and how can we mitigate the situation? This paper looks at the whole problem holistically and thereafter suggests a viable means to create a vibrant, liquid, just, stable and sustainable economic and monetary system, i.e. the Interest-free Gold-based Electronic Netting System (IGENS).

\section{LITERATURE REVIEW}

\subsection{Overview of Problem}

Many scholars have looked into the problem at hand and have provided some explanations to the phenomenon. While most touch on its causes at the surface and provide what may be termed as stopgap measures, others have attempted to explain the root of the problem and suggest some lasting solutions. Lietaer (2001), Greco (2001), Meera (2002a, 2002b, 2004), and many other scholars identified the nature of money and monetary structure as a significant root cause of the problem, i.e. (a) fiat money; (b) fractional reserve banking; and (c) compound interest. These are basically the characteristics of money and banking in most, if not all, countries. 
The monetary and financial system of today is portrayed as indispensable for the healthy growth of an economy. Nonetheless, on the contrary, the current system that is based on fiat money and interest charges is responsible for a whole range of socio-economic, environmental and political problems of the modern world. Monetary experts and economists have argued elsewhere that the monetary and banking system of today is responsible for the widening gap in income and wealth distribution among people of almost all nations (see Stiglitz, 2013 and Piketty, 2015). The Straits Times, January 18, 2016, reported the following findings of Oxfam:

The wealthiest 62 people now own as much as half the world's population, some 3.5 billion people, as the super-rich have grown richer and the poor poorer.

The wealth of the richest 62 people has risen by 44 per cent since 2010, while the wealth of the poorest 3.5 billion fell 41 per cent, Oxfam said in a report released ahead of the World Economic Forum's annual meeting in Davos, Switzerland.

The structure of the monetary system is also responsible for the ever-increasing inflation and the creation of the poor and destitute in the economy. It is responsible for the ever-increasing price of homes, thereby making home-affordability beyond the reach of many. It is also responsible for the trade-off between inflation and unemployment, what is normally known as the Philip's Curve. Therefore, it is argued that unemployment is a phenomenon of the modern monetary system. Hence it is also responsible for the everincreasing indebtedness of individuals, businesses and the government. Even young people in their twenties, who are yet to taste what life is, are made bankrupt by the system. The monetary system also contributes towards the destruction to the environment and the global climate change. It creates a huge disparity in income and wealth distribution. The $1 \%-99 \%$ debate in the US is a testimony to this. Not only in the US, is indeed the whole world moving in this direction. In the US presidential debate on October 14, 2015, the presidential candidate Bernie Sanders mentioned that $1 \%$ of US population owns more than 90 percent of wealth. All these also have caused child-rearing an opportunity cost to retiring comfortably. Hence many nations are now facing shrinking populations that come with aging problems and labor shortages. Such statistics are truly 
manifestations of the interest-based fiat monetary system. Notwithstanding all those, the system is however portrayed as indispensable for an efficient functioning and growth of an economy.

However, people in some countries have taken to the streets to protest against what they regard as crippling wealth and income inequality, corporate greed and government policies that are bias towards the elites. India's former Prime Minister Manmohan Singh, for example, stated, "There are reasons why people are protesting. People are protesting in Wall Street, in Europe about the fat salaries that the bankers are getting when people are being asked to tighten their belts" (Singh, 2011).

In Europe, it is worth noting what the system has particularly done to the people of Greece. Elderly people could not even withdraw their own savings from their banks. Unemployment hit sky-high levels and its economy simply had collapsed. But, surely the people of Greece have needs to be fulfilled, i.e. having demand for goods and services, while at the same time, there are those who are willing to work and produce those goods and services. So what is stopping them from producing and consuming among themselves? Why are so many people unemployed and businesses collapsed?

The answer is lack of 'liquidity'. There is simply not enough liquidity in the economy. Most governments increase the required liquidity by injecting more money into the system, like printing new money and spending them into the economy. Greece had problems doing this because it had already surrendered the power to issue money to the ECB when it joined the euro block. But printing and injecting money is not the only way to enhance liquidity. Liquidity can be increased through other non-monetary means like payment systems based on netting. Fast and efficient electronic payment systems of today are promising tools that can increase liquidity into the economy, at very low costs. This is, therefore, a promising path concerned governments and people can take in order to overcome the myriad negative-effects of the modern interest-based fiat money monetary system of today. The main objective of this paper is to illustrate this, i.e. the benefits of netting systems. 


\subsection{The Purpose and Nature of Money}

Money is perhaps the most known thing to mankind. Everyone, small to big, poor to rich, knows what money is and perhaps crave for it. Since childhood we've been conditioned to love it because we could buy things that we like using money. However not many people truly understand what money is. The famous $20^{\text {th }}$ century economist, John Maynard Keynes, is quoted to have said "I know of only three people who really understand money. A professor at another university; one of my students; and a rather junior clerk at the Bank of England."

When we look back into the history of money, we note that mankind had invented money basically to solve the two major barter problems, i.e. 1) double coincidence of wants; 2 ) indivisibility of items of exchange. These two problems were obstacles to exchange.

As mentioned earlier, compound interest is an integral part of the present monetary system. Compound interest means interest over interest. For example if one were to deposit RM1,000 at a compound interest of 10 percent per annum, one would have RM1,100 at the end of the year, i.e. RM1,000 principal and RM100 as the interest. In the following year, this balance would grow to RM 1,210 , i.e. 10 percent of RM 1,100 is $R M 110$, added to the beginning balance of RM 1,100. A simple formula relates this ending balance known as Future Value (FV) to the initial amount known as the Present Value (PV), i.e. $F V=P V(1+i) n$ where $i$ is the interest rate and $\mathrm{n}$ is the number of years. Accordingly, the second-year balance can be obtained as FV $=1000(1+0.10) 2=1,210$. The tenth-year balance, for example, would then be FV $=1000(1+0.10) 10=$ $2,593.74$. Note that since the formula has a power $n$ in it, it is therefore exponential in nature. In fifty years, the balance would be RM117,390.85 while in a hundred years it is a whopping RM $13,780,612.34$ ! This computation is well-known to many of us, but what perhaps most of us unaware of is that it has serious implications for society, economy and the environment.

The reason why it is postulated that compound interest is significantly at the root of the global chaos of today is that under the present fiat monetary system, most money is created through mere accounting entries by commercial banks, created in the form of loans, which carry compound interest with it. Due to this reason, 
both money and debt grow exponentially within the economy. But nonetheless the real productive economy, i.e. the economy that produces goods and services, does not and cannot match the exponential growth of money and debt. This is where root of the whole global problem lies (see Figure 1 below).

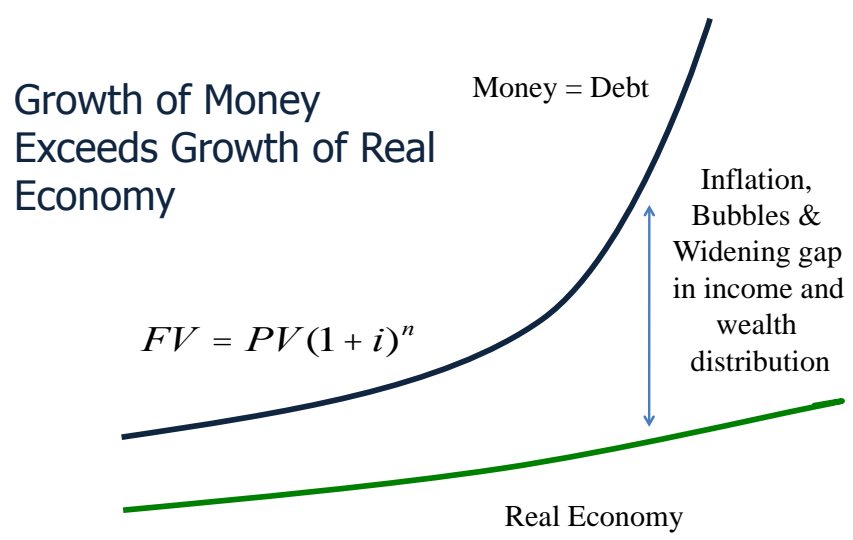

Figure 1.

Growth of Money

As a consequence, money and debt overshoot the real economy, the difference of which shows up in the form of inflation and bubbles, particularly stock market and housing bubbles. In the process, individuals, businesses and governments become increasingly indebted (see Figure 2 below). This exponential growth of money also causes a widening gap in income and wealth distribution among the subjects in the economy. When the average debt level reaches a point that is unbearable for the average entity in the economy to bear, it then 'bursts', causing an avalanche of foreclosures of properties and the 'destruction' of money in the process, which in turn brings about economic recession, unemployment and so forth. Accordingly, during times of crises if one were to take a helicopter-view of the economy below, one would see things seem so normal down there, yet what really happens is that huge transfer of wealth takes place, from those who are distressed by the debt-situation to a small group of people, who are advantaged by the system. This is the fundamental reason why the number of 
billionaires in the world actually increased substantially since the 2007 US subprime mortgage crisis.

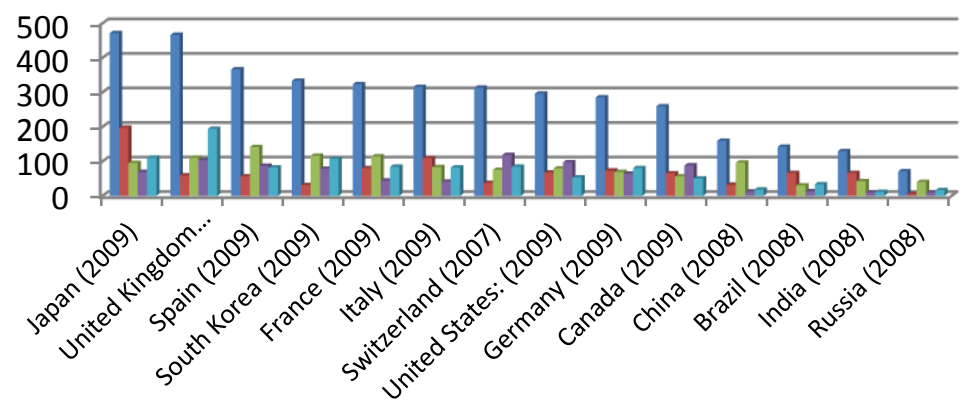

- Total $\square$ Government $\square$ Nonfinancial Business $\square$ Households $\square$ Financial Institutions

Figure 2.

Total Debt in Selected Countries around the World, as per the years mentioned, as percent of GDP

The world, after being under such pure fiat money system for the past few decades, has been brought to the current precarious position we are currently observing. There is now a global debt crisis, a situation significantly brought about by fiat money and compound interest. This is the reason why a highly productive nation like Japan, a nation full of hardworking and intelligent people, has fallen into a receding economy since more than two decades ago. In a real economic system, one would expect such people to be able to produce abundantly and thereafter lend to others any extra they might save. And yet, in a fiat money compound interest-based system, Japan has come to belong among countries with the largest total debt as a percentage of GDP, i.e. more than $450 \%$, with the government debt alone amounting to almost $200 \%$ of GDP. Note that government debt is indeed also debt of the people.

The compound interest-based monetary system, therefore, strengthens a small section of the economy at the expense of the whole system itself. Hence compound interest is a seed of a nation's 
own destruction; the destruction of which we are observing globally today. While strengthening a small group of people, it brings about outright distress on the rest of the people-economic deprivation, inflation, social disparity, destruction of ecosystems and environment, high crime levels, erosion of moral values, collapse of the institution of family, erosion of feelings of love and compassion for others, etc.

Accordingly, the compound interest monetary system has also brought the world to an interesting historical juncture, i.e. almost every nation facing political upheavals and challenges, locally and internationally, due to this precarious position we are currently in. At this juncture, we are reminded of the Arab Spring in the Middle East that was triggered by the act of one individual's selfimmolation, as a reaction to serious economic deprivation.

Government debt, being the debt of the people, would have to be paid through collection of taxes and other revenues from the people. This is a reason why in the case of Greece, for example, draconian austerity measures were required of its citizens. Accordingly one could also see the anger against the monetary and banking system worldwide. In good times banks collect interest while in bad times, i.e. default-periods, they collect real assets placed as collaterals.

Nyazee (2008) has ably illustrated, using the fine methodology of classical scholars, that fiat money, which is basically a debt issued by the government, is fundamentally a form of riba itself.

\section{GOLD-NETTING AS A SOLUTION TO THE GLOBAL ECONOMIC MONETARY AND ECONOMIC CRISES}

Experts have suggested a number of ways to mitigate the current global economic crisis. This article argues for gold-netting as a viable and desired solution.

As mentioned earlier, experts have traced the flaws in current monetary system to: (a) fiat money; (b) fractional reserve banking; and (c) interest charges. Islamic banking and finance of today is presented as interest-free finance. However, in most if not all countries, it works within the fiat money and fractional reserve banking environment. Indeed, Islamic finance working within such 
background causes it to converge with conventional finance due to arbitrage profiteering made possible between the two financial systems. Hence to make Islamic finance to define itself, this arbitrage possibility need to be eliminated. One way to address this issue is through the use of real money concepts - like gold standard, silver standard, gold dinar, etc. We have postulated that real money concepts would significantly reduce if not eliminate the problems of fiat money discussed earlier, and hence the wisdom behind why shari'ah principles of mu'amalat, hudud, mahr, and others were all revealed with gold and silver as the monetary standards. Real money, like the gold dinar, indeed solves the first two 'problems' of the present day monetary system, i.e. fiat money and fractional reserve system.

The issue at hand now is designing a money and payments system that can avoid all the above-discussed socio-economic-environmental problems, i.e. one that would promote economic justice, stability and sustainability. To realize and appreciate solutions it is best we go back to the drawing board and start from scratch, i.e. the fundamentals of money.

\subsection{Type of Data and Location of Research}

Mankind basically needed money to solve the two fundamental problems of barter exchange, i.e. (a) double coincidence of wants; and (b) divisibility. Ingeniously, mankind invented medium of exchange that can address and solve those problems. To achieve this objective, a reference point was needed, against which the value of all other things could be measured. This reference point needs to have the following characteristics in order to effectively address the problems associated with barter:

a. Having intrinsic value - i.e. people desire it for its own sake, i.e. people derive utility from it and hence it need not be imposed on people through law. The monetary item, therefore, should not have any seigniorage over its actual value. Fiat money on the contrary, for example, has significant seigniorage and is imposed on people using the legal tender law.

b. Accepted by society - i.e. a social contract to accept the thing as a common measure of value. 
c. Divisible - this is an important characteristic since divisibility is one of the problems of barter.

d. Homogenous - this characteristic is pertinent as it enhances the divisibility character. It means if the item is cut into equal smaller units, one need not ask which unit one prefers since they are all equal.

e. Mobile - can be easily moved about.

f. Durable - i.e. long lasting. So that it can also be saved for future use.

g. Rare - having high value over quantity (or weight) ratio. Hence a small amount having high value.

h. Having not much industrial or seasonal demand. This would give a stable value-relationship with other things.

With the above eight characteristics an item can, therefore, be a stable measure of value, i.e. a reference point for all exchanges, i.e. measure value of goods, services, investments, etc., across time and space. Because it's a reference point, it is not traded as a commodity. It is, therefore, also not an investment item, but rather it measures investments and their outcomes.

Precious metals like gold and silver fulfill all the above characteristics. Items like wheat, barley, salt, and dates as mentioned in one hadith fulfill all but perhaps the last two. So they still can play the role of money for smaller transactions within given short periods of time. The first six characteristics are pertinent while the last two are additional desired characteristics.

A unit of the reference point is what money effectively is. Historically, various commodities with the above characteristics have been used as money. Such commodities include cowry shells, salt, wheat, barley, gold, silver, etc. People accept them for their own accord since these items have their own intrinsic value from which people derive utility.

Some points require special attention here. Firstly, although commodities with intrinsic value have been used as money, money itself however cannot be treated as a commodity. To elaborate this, it can be said that money is indeed a commodity or a standardized service that fulfills all the above mentioned characteristics of 
measure of value and it acts as a reference point against which the value of all other things are measured; but nevertheless it cannot be the subject matter of a contract by itself, hence cannot be sold or leased. The overall concept of money is illustrated in Figure 3 below ${ }^{2}$ :

The concept of money starts with Problems of Barter Exchange

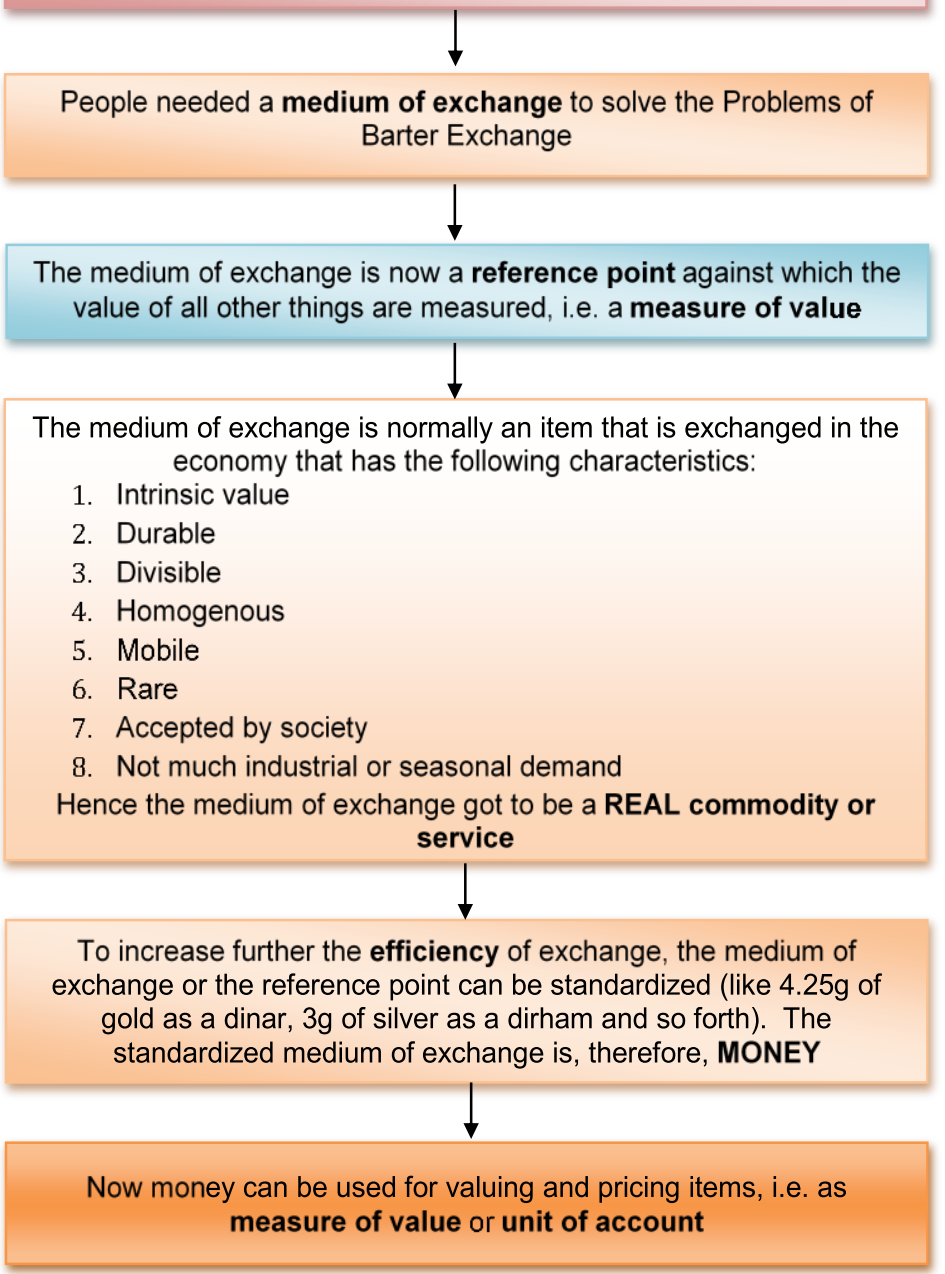

Figure 3.

The Concept of Money Defined

2 Reproduced from Meera and Mubasheera (2015). 


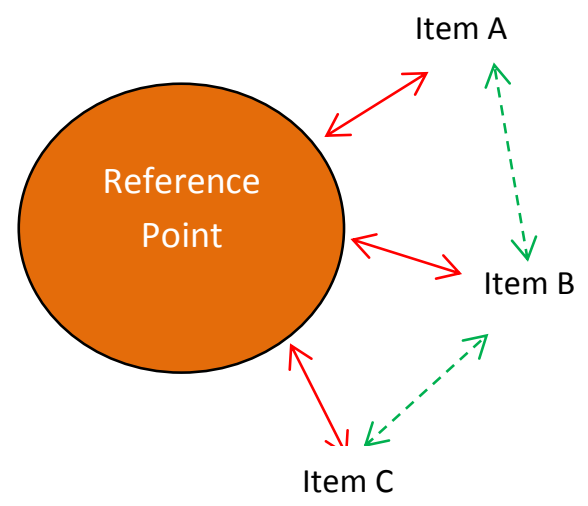

Figure 4.

Money as Medium of Exchange (Commodity) and as Unit of Account or Measure of Value (Information)

$\longleftrightarrow$ When the reference point, like gold dinar, is used for, say, buying item $A$, then it is being used as a medium of exchange. Here money is a COMMODITY and being exchanged for another real thing. It is effectively like a barter exchange and a fair transaction because both of the items exchanged have intrinsic value.

$<---\rightarrow$ When the reference point, like gold dinar, is used for pricing, say item $A$ and item $B$ as being one dinar, then it is being used as a measure of value or unit of account. Hence $A$ and $B$ can be exchanged directly without using gold dinar at all. Here, money is INFORMATION.

The overall concept of commodity money is beautifully expressed in the following hadith.

Abu Said al-Khudri reported Allah's Messenger s.a.w. as saying: Gold is to be paid for by gold, silver by silver, wheat by wheat, barley by barley, dates by dates and salt by salt, like for like, payment being made on the spot. If anyone gives more or asks more he has dealt in riba. The receiver and giver are equally guilty. (Sahih Muslim) 
All the above-mentioned commodities by the Prophet (s.a.w) have all the six main characteristics of money and they all had indeed played the role of money at one point in history or another.

Now if money does not have any intrinsic value, like fiat money, then the exchange process will manifest an 'unjust exchange'. This is because, the person who is receiving the commodity gets a real asset, while the rest of the economy, that is getting the money would be disadvantaged since fiat money does not have any intrinsic value. This injustice is however true only for the first exchange but, nonetheless, this still constitutes injustice, i.e. the seigniorage ${ }^{3}$. As a consequence, the asset ownership structure in the society would also be gradually changed, on a continual basis, by this fiat money system where those who create fiat money would then become the ultimate owners of tangible resources, basically in exchange for 'nothing', as the cost of mere printing money is effectively zero.

Hence a pivotal flaw of the current fiat monetary system is that its capacity of money creation out of thin air reduces the monetary value of the real assets in an economy. The amount of utility derived from those assets, for a given amount of money, tends to erode gradually as too much money chases too few goods.

This concept of money where primarily it is a 'measure of value' is inbuilt in the very structure of the Islamic economic system. The amount of zakat, hudud punishment, diah, mahr, etc. have all been explicitly defined using gold and silver as the monetary reference points. Even now, when the monetary system is fiat in nature, we use gold and silver as a 'measures of value' perhaps without being aware of the fact. For example, we determine the amount of zakat payable on cash holdings by calculating the equivalent monetary worth of a certain amount of gold or silver having in possession, i.e. the nisab, which in Malaysia is $85 \mathrm{~g}$ of gold (equivalent to 20 dinars).

This primary function of money as a 'measure of value' requires special attention in the current monetary and financial

3 Seigniorage is the additional value given to money over and above its intrinsic value. For example, say the cost of printing a 100-ringgit note is 20 cents. Then the seigniorage is RM99.80. This is additional freely obtained purchasing power. 
system, where now the main function of money is as 'medium of exchange'. It is also propagated that anything generally accepted by the people, or forced through law to be accepted, is regarded as money. However, such injunctions violate the basic concepts of justice and equitable distribution of wealth. Hence a fundamental flaw of the current monetary system is the absence of a just and equitable 'measure of value'.

We should understand that as fiat money does not have any intrinsic value, people are forced to accept it as money by the authoritative bodies via the legal tender law.

However in the current era of advanced information technology, it is possible to use a lot of things as symbolic money like paper money, e-money, etc. where something convenient being used for day to day transactions, yet it is $100 \%$ redeemable and backed by some commodity with intrinsic value.

\subsection{Designing a Just, Stable and Sustainable Monetary System}

Having argued how the characteristics of present-day monetary system are indeed behind the global volatile, unjust and unsustainable monetary and economic systems, we provide below an interestfree gold-based electronic netting system, which we call IGENS, that can possibly mitigate the above problems of the interest-based fiat monetary system, thereby bringing about a whole system that is just, stable and sustainable. Note that the proposed system has four main characteristics, namely: (a) interest-free; (b) gold-based; (c) netting system; and (d) electronic. Let's see why these characteristics can bring about a monetary system that is just, stable and sustainable.

Firstly, why interest-free? This is the easiest to answer. It is by consensus of most scholars agreed that interest charging is riba that is strongly prohibited in Islam. This is in fact one of the salient features of Islamic monetary, financial, and economic system. However technically, by being interest-free it does not cause an exponential growth in money and debt in the economy, as is the case with the present monetary system, which is highly inflationary, destabilizing and unsustainable 4 . Accordingly, it does not transfer

4 See Lieataer (2001) and Meera (2004). 
wealth unjustly among the subjects in the economy and thereby does not contribute towards the widening gap of income and wealth distribution. At international level, this translates to protecting the wealth and sovereignty of nations ${ }^{5}$.

Why then gold-based? From our earlier discussion on the characteristics of good measure of value, and hence money, gold fulfilled all the eight criteria beautifully. Since it is real, it cannot be created at will like fiat money. Therefore, gold does not give any unfair seigniorage benefit to any country, like the main international currencies of today like the dollar, pound, and so forth. Hence goldbased monetary systems would be much more stable and inflationfree. Numerous studies have shown that gold is an effective hedge against inflation. This is much evidenced from history (see Jastram, 1977). The limited quantity of gold in the world is not a short-coming but rather a plus point. This is because we need gold more to play the role as a measure of value rather than medium of exchange. The limited quantity can be compensated by the velocity of money circulation; in other words, the same money can be used again and again in many transactions.

Why credit and netting? Credit allows one to engage in an economic exchange transaction without having money at that point in time. Hence in a credit-based system, shortage of money or liquidity can be easily overcome. Shortage of money is a significant cause of recession, fall in business, rise in unemployment, etc. What nations like Greece is going through, even though its problems are generally said to be of sovereign debt, is shortage of liquidity that is much responsible for the serious economic recession faced there. Unfortunately for Greece, being part of the euro-zone it is unable to 'print' its own money and solve the problem. On the contrary, it was forced to accept additional euro loans at draconian terms. Accordingly, while credit-based payment system substantially increases liquidity, the netting process periodically cancels out huge volumes of counter-debts. In this way, large amounts of transactions are made possible with the least amount of money. This is illustrated in Section 3.3 below.

5 See Meera and Larbani (2006a, 2006b). 
If the whole netting system is implemented within a group like a locality, a town, a village, a chamber of commerce, a cooperative or simply among a like-minded people that would give people the choice of being a member of the system or remain in the present fiat money system. This is important since it gives people to make their own choice, without being forced by any party.

Why electronic? Well, simply to take advantage of the advancements in modern information technology. Using electronic payment systems is fast, efficient, and mobile and could be easily monitored and audited real-time. This is also in tandem with the globally rising modern electronic payment systems ${ }^{6}$.

\subsection{The Principles of Netting}

Netting basically avoids or minimizes the use of money as medium of exchange. On the contrary, money as measure of value or money as information is emphasized. The principles of netting can be illustrated as follows.

Example 1: A sees from electronic notice board that $B$ is offering car servicing, $C$ is the local physician, D the local grocer wants some freshly baked bread. A negotiates with B for her car serviced for $\$ 100$ in cash. $B$ receives her medical treatment from $C$ for $\$ 100$. A delivers bread to $D$ for $\$ 100$ while $C$ obtains his weekly grocery from $D$ for $\$ 100$. We may tabulate the transactions in a matrix like in Table 1 below:

Table 1.

Matrix of Sales and Purchases

\begin{tabular}{cccccc}
\hline & A & B & C & D & Total Sale \\
\hline A & - & & & 100 & 100 \\
B & 100 & - & & & 100 \\
C & & 100 & - & & 100 \\
D & & & 100 & - & \\
\hline Total Purchase & 100 & 100 & 100 & 100 & 400 \\
\hline
\end{tabular}

\begin{tabular}{cccc}
\hline & Total Sales & Total Purchases & Net Sale \\
\hline A & 100 & 100 & 0 \\
B & 100 & 100 & 0 \\
C & 100 & 100 & 0 \\
D & 100 & 100 & 0 \\
\hline
\end{tabular}

6 These include for example crypto currencies like bitcoin and payment systems like AliPay, ApplePay, Commercial credit circuits, etc. 
Since each party sold $\$ 100$ worth of goods/services and purchased $\$ 100$ dollars of goods/service, the net of sales and purchases for each person is zero. Hence the transactions all together cancel out each other and therefore no one needs to pay anyone. Note that $\$ 400$ dollars of transactions have taken place without the use of any money at all as medium of exchange. However of course in real-life, transactions may not net-off cleanly as in the above example. A more realistic example would have been like below:

Example 2: A sees from electronic notice board that $B$ is offering car servicing, $C$ is the local physician, $D$ the local grocer wants some freshly baked bread. A negotiates with B for her car serviced for $\$ 150$ in cash. D also gets his truck repaired for $\$ 300$ from B. A also gets some grocery from $D$ for $\$ 80$. B receives her medical treatment from $C$ for $\$ 100$. A delivers bread to $D$ for $\$ 120$ while $C$ obtains his weekly grocery from $D$ for $\$ 100$ and some freshly baked bread from $A$ for $\$ 20$. Table 2 below shows the matrix of transactions:

Table 2.

Matrix of Sales and Purchases

\begin{tabular}{cccccc}
\hline & A & B & C & D & Total Sale \\
\hline A & - & & 20 & 120 & 140 \\
B & 150 & - & & 300 & 450 \\
C & & 100 & - & & 100 \\
D & 80 & & 100 & - & 180 \\
\hline Total Purchase & 230 & 100 & 120 & 420 & 870 \\
\hline
\end{tabular}

\begin{tabular}{cccc}
\hline & Total Sales & Total Purchases & Net Sale \\
\hline A & 140 & 230 & $(90)$ \\
B & 450 & 100 & 350 \\
C & 100 & 120 & $(20)$ \\
D & 180 & 420 & $(240)$ \\
\hline
\end{tabular}

Now note that $\$ 870$ dollars of transactions have taken place but only $\$ 350$ needed to settle the whole trade matrix. Hence, even though the netting is not perfect, clearly there is benefit to netting, i.e. large amount of trade is accomplished with much lesser amount of cash. 
The above simple netting structure has many economic benefits. These, and the benefits of the gold-based and interest-free structure are summarized below:

\section{BENEFITS OF NETTING}

a. There would be no 'shortage of money' that dampens business, which is generally the situation during recessions.

b. It is basically an accounting system that increases liquidity without creating money out of thin air.

c. It provides abundant liquidity cheaply, as though the 'right to create money' is vested in the hands of everyone and not just the banks alone.

d. Increased liquidity promotes trade, business, employment, and profits.

e. Netting is like producing amalgamated accounts of all parties where debtors and creditors in the accounts tend to cancel out.

f. Netting monetizes real assets, goods, and services, hence in a way redefines money.

g. In netting, no transfer of debt is involved.

h. For Islamic finance one need not resort to the helah of tawarruq or commodity murabahah for financing working capital.

\section{BENEFITS OF GOLD-BASED}

a. Provides a stable 'measure of value' that is missing in present global monetary structure which is important for fair and just economic exchanges.

b. There is no 'monopoly' of international preferred currency.

c. There is no unfair seigniorage accruing to any privileged party.

d. It is non-inflationary by structure because credit is created only when goods and services are created and exchanged.

e. It is stable and non-cyclical.

f. It is akin to a fixed-exchange-rate regime.

g. No currency risk is involved, therefore it eliminates speculation and arbitrage that are possible in currency markets; which in turn eliminates the need for derivative markets like forward, futures and option markets on currencies, to mitigate the currency exchange risk.

h. It protects the wealth of people and sovereignty of nations which is one of the Maqasid of al-Shariah. 


\section{BENEFITS OF NON-INTEREST-BASED}

a. Does not cause an exponential growth in money and debt, as is the case with the present monetary system, which is highly inflationary, destabilizing, and unsustainable.

b. Does not transfer wealth unjustly; also protects the wealth and sovereignty of nations.

c. Does not contribute towards the widening gap of income and wealth distribution.

d. Promotes cooperation in the economy rather than competition.

e. Promotes stability and sustainability of the economy and environment.

\subsection{Implementing Interest-free Gold-based Electronic Netting System (IGENS) within the Current Socio-Economic-Political Scenario}

Even if the IGENS is desirable, it is not advisable to change the whole monetary system abruptly. Doing so could bring about more harm than good. Current international political interests may not also allow large-scale implementation of IGENS due to the huge seigniorage benefits embedded in international currencies. Accordingly, we suggest that IGENS is initially implemented only on a small scale within small communities. Such communities could be cooperatives, chambers of commerce, clients of banks, regional communities, or any group of people, businesses, and government. In this way, people could have the choice whether they want to be part of IGENS or not.

Some examples of netting systems that already exist globally are:

1. Bilateral and multilateral payment arrangements (BPAs and MPAs) ${ }^{7}$. BPAs and MPAs are done by central banks to net-off international trade balances. Countries that are parties to such agreements would pass the letter of credit in international trade financing through the central banks. Transactions are recorded and accumulated for a period of time before being net-off. Only balances after the netting is settled among the countries.

7 For a discussion on deriving an efficient trade matrix among nations, using mathematical programming techniques, where trading needs of countries are fulfilled with the minimal settlement, please see Meera and Larbani (2004). See Cheong (2003) on the benefits and practical ways of implementing BPA's and MPA's. 
BPAs and MPAs have a lot of benefits, particularly the need for foreign reserves for trade is very much diminished. Even countries with minimal foreign reserves can now trade. Also in these arrangements firm risk is translated into sovereign risk. Hence this is very suitable for countries where counter party risk is very high, like countries in war-time, etc. Malaysia for example has BPA arrangements with about twenty countries.

2. Local exchange trading schemes (LETS). These are complementary currency systems used by local towns and regions to boost the local economy and employment. Transactions between subjects are recorded on a credit basis and net-off periodically. LETS increases liquidity into the system and makes a lot of transactions without the use of national currencies. Since the money is local money, it boosts business and transactions within the community and hence boosts the local economy and standard of living. There are many LETS systems working worldwide - more than 43 LETS in Western Australia, KitchenerWaterloo, Halifax in Canada, Venezuela has many with the support of the government, Europe, and Japan.

3. Commercial barter exchanges. Barter exchanges basically exchange goods and services. By keeping records of exchanges, measured in some currency, the parties are able to minimize the use of currencies and circumvent foreign exchange risk. There are hundreds of barter exchanges in the world. The Business Exchange (TBEx) in Aberdeen, Scotland operated by Richard Logie is one successful model.

4. Commercial credit circuits (C3). The commercial credit circuit (C3) is a netting process that provides cheap and quick working capital particularly to small SME's. The Social Trade Organization (STRO) of Netherlands has created an open-source software called CYCLOS that enables the implementation of C3 online or using mobile platform. C3 is successfully implemented in Uruguay and other parts of South America.

5. WIR Bank in Switzerland. One of the oldest netting systems, the WIR Bank gives billions of dollars of credit to its members, originally interest-free but now with minimal interest charges. Businesses may finance working capital needs fast, efficient, with minimal interest charges. This increases liquidity, business 
transactions, profitability, and employment with minimal use of national currency.

The netting system can also be used to design a truly Islamic credit card system. The existing present Islamic credit card systems mostly are modeled after the conventional credit card systems, and hence the frequent criticisms level against it. For a discussion on how an Islamic credit-card system can be designed within a netting arrangement (muqassah) please see Bilal and Meera $(2015)^{8}$.

\section{CONCLUSION}

The paper argued for the benefits to be reaped by nations by implementing interest-free gold-based electronic netting system (IGENS) within the current global economic scenario. The IGENS is argued to be contributing towards economic justice, stability and sustainability. Indeed these are highly pertinent in today's global economic condition that is plagued with crises, with much environmental destruction and non-sustainability. Indeed sustainability is the current buzzword in economic development, such that United Nations has come up with a new method for measuring development and wellbeing, i.e. the inclusive wealth index ${ }^{9}$.

Accordingly, we postulate that nations should allow multiple money and payment systems to operate in the economy, particularly those that are based on real money and netting concepts. Real money concepts do not cause inflation in the economy, while the netting process increases liquidity, cheaply, and abundantly. Abundant liquidity, in turn, encourages business, employment, and profits. Such multiple payments systems would also add resilience to the economy and able to absorb domestic and international shocks better.

A netting system based on gold is not necessarily one where people need to carry around physical gold here and there, but rather one based on mobile-money or other electronic means. Electronic money and payment systems are most desirable for today's

8 Z Consulting Group Sdn Bhd, Malaysia is currently developing a software to operate the muqassah-based Islamic credit card system.

9 Please see UNU-IHDP and UNEP (2014). 
circumstances; and governments of today should strongly support, implement and regulate such systems. The proposed payments netting system is indeed much alike the bilateral (BPA) and multilateral (MPA) payment systems that central banks employ to settle balances among themselves, but however now implemented at the individual-business-government level. 


\section{REFERENCES}

Bilal, M. \& Meera, A. K. (2015). Al-Muqassah model: An alternative shariah-compliant Islamic credit card model for Islamic financial institutions in Malaysia. International Journal of Islamic and Middle Eastern Finance and Management, 8(4), 418-438.

Cheong, L. M. (2003, September). Gold in international trade. Paper presented by the Deputy Governor of Bank Negara Malaysia in Kuala Lumpur International Conference on Gold in International Trade, September 2003.

Greco, T. H. (2001). Money: Understanding and creating alternatives to legal tender. Vermont: Chelsea Green.

Jastram, R. W. (1977). The golden constant. New York: John Wiley \& Sons.

Lietaer, B. (2001). The future of money. London: Random House.

Meera, A. K. M. (2002a). Proceedings of the 2002 International Conference on Stable and Just Global Monetary System, Kuala Lumpur, 19-20 August 2004. International Islamic University Malaysia.

Meera, A. K. M. (2002b). The Islamic gold dinar. Kuala Lumpur: Pelanduk Publications.

Meera, A. K. M. (2004). The theft of nations: Returning to gold. Kuala Lumpur: Pelanduk Publications.

Meera, A. K. M., \& Larbani, M. (2004). The gold dinar: The next component in Islamic economics, banking and finance. Review of Islamic Economics, 8(1), 5-34.

Meera, A. K. M., \& Larbani, M. (2006a). Part I: Seigniorage of fiat money and the maqasid al-shari'ah: The unattainableness of the maqasid. Humanomics, 22(1), 17-33.

Meera, A. K. M., \& Larbani, M. (2006b). Part II: Seigniorage of fiat money and the maqasid al-shari'ah: The compatibility of the gold dinar with the maqasid. Humanomics, 22(2), 84-97. 
Meera, A. K. M., \& Mubasheera, H. (2015). Revisiting the concepts of money, profit and interest from the perspective of value and diminishing marginal utility. Journal of Islamic Monetary Economics and Finance, 1(1), 25-53.

Nyazee, I. A. K. (2008). The concept of riba and islamic banking. Islamabad: Niazi Publishing House.

Piketty, T. (2015). The economics of inequality. Belknap Press.

Singh, M. (2011, October 20). Singh swims with civil society tide Anna to Wall Street protest, PM soft. The Telegraph. Retrieved from https://www.telegraphindia.com/1111020/jsp/frontpage/ story_14646335.jsp

Stiglitz, J. E. (2013). The price of inequality. W. W. Norton \& Company.

UNU-IHDP \& UNEP (2014). Inclusive wealth report 2014: Measuring progress toward sustainability. Cambridge: Cambridge University Press. 